\begin{tabular}{l} 
Sharif University of Technology \\
Scientia Iranica \\
SCIENTIA \\
IRAN \\
Thansactions A: Civil Engineering \\
\hline
\end{tabular}

\title{
Enhanced vibrating particles system algorithm for damage identification of truss structures
}

\author{
A. Kaveh ${ }^{\mathrm{a}, *}$, S.R. Hoseini Vaez ${ }^{\mathrm{b}}$, and P. Hosseini ${ }^{\mathrm{b}}$ \\ a. Centre of Excellence for Fundamental Studies in Structural Engineering, School of Civil Engineering, Iran University of Science \\ and Technology, Tehran-16, Iran. \\ b. Department of Civil Engineering, Faculty of Engineering, University of Qom, Qom, Iran.
}

Received 17 February 2017; received in revised form 23 July 2017; accepted 14 August 2017

\section{KEYWORDS \\ VPS algorithm; \\ Enhanced VPS \\ algorithm; \\ Damage detection; \\ Truss structures; \\ Inverse problems; \\ Optimization.}

\begin{abstract}
Vibrating Particles System (VPS) optimization is a recently developed metaheuristic algorithm for optimization. This algorithm is inspired by the free vibration of freedom systems' single degree with viscous damping. In this method, each answer is modeled as a particle that moves to its equilibrium position; new positions of the vibrating particle system are updated according to a historically best position. Enhanced Vibrating Particles System (EVPS) uses new approaches to improve the performance of the VPS algorithm. In this study, a dynamic method and modal based approach consisting of natural frequencies and mode shapes are used in the objective function formulation. To demonstrate the performance of the VPS and EVPS, different truss structures including several multiple elements scenarios with noise and without noise in modal data are considered for detecting damage problems. Additionally, all scenarios are studied with significant mutations. Results show that the EVPS algorithm has reached better answer than the VPS algorithm for damage detection problems.
\end{abstract}

(C) 2019 Sharif University of Technology. All rights reserved.

\section{Introduction}

Optimization is a highly significant and prevalent topic in engineering, which leads to the correct use of funds, time, and materials [1-4]. Metaheuristic algorithms are common tools for optimizing problems in suitable time, but they cannot ensure gaining the best answer. New metaheuristic algorithms seek to present methods resulting in more efficient answers for various problems in reasonable computational time. These methods are quite well-known in the structural optimization field. Some of these methods are listed as follows: genetic algorithms [5], particle swarm optimization [6],

\footnotetext{
*. Corresponding author. Tel.: +982144202710;

Fax: +9821 7r240398

E-mail address: alikaveh@iust.ac.ir (A. Kaveh)
}

charged system search algorithm [7], krill-herd algorithm [8], simplified dolphin echolocation algorithm [9], colliding bodies optimization [10], enhanced colliding bodies optimization algorithm [11], eagle strategy with differential evolution [12], ray optimization [13], accelerated water evaporation [14], and modified dolphin monitoring [15] (this method can be applied to every metaheuristic method to improve their performance). Vibrating Particles System (VPS) algorithm has recently been developed by Kaveh and Ilchi Ghazaan [16].

Structural damage detection has been an active topic of increasing interest in structural engineering during the last few decades [17,18]. Monitoring the health of structures and infrastructures exposed to aging or extreme loadings is nowadays recognized as a societal need [17]. Detecting damage includes all the techniques and methods utilized for identifying the damages and their locations and severity. Damage detection methods are divided in two types: static 
and dynamic. The dynamic methods are based on evaluating the changes in structural dynamic characteristics and the theoretical basis of these methods is that damage causes changes in dynamic characteristics of structures. Also, there are two classes of dynamic methods consisting of signal based and modal based.

In this study, Enhanced Vibrating Particles System (EVPS) is introduced and then, VPS and EVPS algorithm are utilized for damage identification of truss structures. Damage identification using metaheuristic methods in truss structures is utilized for finding the severity of the damage in each element of truss structures according to changes in natural frequencies and mode shapes. Different metaheuristic algorithms are applied to damage identification by many researchers [19-23]. These types of problems are considered using finite element models and the error should be equal to zero to obtain the exact answer. It is obvious that the error will never be zero if noise is considered in modal data. Most of the elements are undamaged, while few are damaged. Accordingly, the algorithm can use a significant mutation to reach the exact answer and it should generate zero value emphatically in this mutation [9]. Hence, the mutation is used for all problems in the study.

This paper is organized as follows: In Section 1, the introduction is presented. A brief explanation of the vibrating particles system algorithm is provided in Section 2. Enhanced vibrating particles system is presented in Section 3. In the fourth section, the formulation of the problem is provided. Section 5 includes four benchmark problems. Finally, the concluding remarks are presented in Section 6 .

\section{Vibrating particles system algorithm}

This section contains 2 parts. The first part provides a brief introduction to the vibrating particles systems, and the second part presents the VPS algorithm.

\subsection{Brief concepts of the VPS}

Free and forced vibrations are two types of vibration. In the free vibration, the system is set in motion by a maintained force, while in the forced vibration, a periodic force (displacement or velocity) is applied to the system. There is always a damping in these systems, sometimes caused by exterior agents like viscous damping and sometimes by internal agents. The purpose is to free the vibration system of single degree of freedom with viscous damping in Kaveh and Ilchi Ghazaan's study [24]. The equation of the free vibration system can be presented as follows:

$$
M \ddot{x}+C \dot{x}+K x=0,
$$

where $M, C$, and $K$ are mass, coefficient of viscous damping, and stiffness of the system, respectively.
Also, $x$ is distance from the position of the stable equilibrium of the system. Critical damping coefficient is provided in Eq. (2):

$$
C_{c}=2 m \omega_{n}, \quad \omega_{n}=\sqrt{\frac{K}{M}},
$$

where $\omega_{n}$ is natural frequency of the single-degree-offreedom system. If $C<C_{c}$ (under damped system), the solution to Eq. (1) is determined as:

$$
\begin{aligned}
& x(t)=\rho e^{-\xi \omega_{n} t} \sin \left(\omega_{D}+\varphi\right), \\
& \omega_{D}=\omega_{n} \sqrt{\left(1-\xi^{2}\right)}, \quad \xi=\frac{C}{C_{c}},
\end{aligned}
$$

where $\rho$ and $\varphi$ are constant and calculated according to the initial condition.

\subsection{VPS algorithm}

In this method, first, the initial locations of particles are created by permissible random numbers in $n$ dimensional search space by:

$$
x_{i}^{j}=x_{\min }+\operatorname{rand} .\left(x_{\max }-x_{\min }\right),
$$

where $x_{i}^{j}$ is the $j$ th variable of the $i$ th particle. $x_{\min }$ and $x_{\max }$ are the starting and ending points of permissible search space for the $j$ th variable, respectively, and rand is a random number in the range of $[0,1]$.

In this method, three parameters are defined as $H B$ (the historically best position of the entire population), $G B$ (a good particle), and $B P$ (a bad particle). These parameters are selected for every particle as: $H B$ is the best candidate until that iteration, $G B$ and $B P$ are selected randomly between partially best and worst answers in each iteration, respectively.

A descending function based on number of iterations is defined in Eq. (5). This parameter is introduced due to the effect of the damping level in the vibration.

$$
D=\left(\frac{i t e r}{i t e r_{\max }}\right)^{-\alpha}
$$

where iter is the number of current iterations, iter $_{\max }$ is the total number of iterations, and $\alpha$ has a constant value. Generating the next population in VPS algorithm is completed using the following equation:

$$
\begin{aligned}
x_{i}^{j}= & \omega_{1} \cdot\left[\text { D.A.rand } 1+H B^{j}\right]+\omega_{2} \cdot\left[\text { D.A.rand } 2+G P^{j}\right] \\
& +\omega_{3} \cdot\left[\text { D.A.rand } 3+B P^{j}\right] \\
A= & {\left[\omega_{1} \cdot\left(H B^{j}-x_{i}^{j}\right)\right]+\left[\omega_{2} \cdot\left(G P^{j}-x_{i}^{j}\right)\right] } \\
& +\left[\omega_{3} \cdot\left(B P^{j}-x_{i}^{j}\right)\right] \\
\omega_{1}+ & \omega_{2}+\omega_{3}=1,
\end{aligned}
$$


where $\omega_{1}, \omega_{2}$, and $\omega_{3}$ are of relative importance to $H B, G B$, and $B P$, respectively, and rand 1 , rand 2 , and rand 3 are random numbers in the range of $[0,1]$. It should be noted that the effects of $A$ and $D$ are equivalent to $\rho$ and $e^{-\xi \omega_{n} t}$ in Eq. (3), respectively, and $\sin \left(\omega_{D}+\varphi\right)$ is assumed as unity in Eq. (3).

A parameter like $p$ (within 0 to 1 ) is defined to accelerate the convergence of the VPS algorithm. This parameter is compared with rand and if $p<$ rand, then $\omega_{3}=0$ and $\omega_{2}=1-\omega_{1}$.

Also, when a particle violates a boundary, it must be changed by the harmony search-based side constraint handling approach [24]. In this method, $H M C R$ (harmony memory considering rate) parameter determines whether the violating component should be replaced by the corresponding value in $H B$ or it must be selected from the permissible search space. Also, if replaced by $H B$, there is a parameter, $P A R$ (Pitch Adjusting Rate), that determines whether this value should be changed with the neighboring value or not. This process is repeated for iter $_{\max }$ times.

\section{Enhanced vibrating particles system algorithm}

In this section, Enhanced Vibrating Particles System (EVPS) is presented. This improvement results in increasing the convergence speed, augmenting the ability of search, helping the EVPS to escape from local optima, and generally gaining better results. Changes in the VPS algorithm are as follows:

In this method, two new parameters are introduced as "Memory" and "OHB". Memory acts as $H B$ with the difference that it saves $N B$ number of the historically best positions in the entire population, and $O H B$ (one of the historically best positions in the entire population) is one row of Memory that is selected randomly. $H B$ is replaced with Memory in the EVPS algorithm. Another change in the VPS algorithm is that Eq. (6) should be replaced with Eq. (7). In Eq. (7), one of the (a), (b), and (c) equations is applied with the possibility of $\omega_{1}, \omega_{2}$, or $\omega_{3}$, respectively.

$$
\begin{aligned}
& x_{i}^{j}=\left\{\begin{array}{l}
{\left[\text { D.A.rand } 1+O H B^{j}\right]} \\
{\left[\text { D.A.rand } 2+G P^{j}\right]} \\
{\left[\text { D.A.rand } 3+B P^{j}\right]}
\end{array}\right. \\
& A=\left\{\begin{array}{l}
( \pm 1)\left(O H B^{j}-x_{i}^{j}\right) \\
( \pm 1)\left(G P^{j}-x_{i}^{j}\right) \\
( \pm 1)\left(B P^{j}-x_{i}^{j}\right)
\end{array}\right. \\
& \omega_{1}+\omega_{2}+\omega_{3}=1,
\end{aligned}
$$

where $( \pm 1)$ are applied randomly. It should be noted that $O H B, G P$, and $B P$ are determined for every particle independently. Other sections of the EVPS are defined exactly same as in the VPS algorithm.

\section{Problem formulation}

In this section, damage identification is presented briefly based on changes in natural frequency and mode shapes. According to the stiffness and mass matrices for each element, global matrices can be generated using Eq. (8). It should be noted that the damping matrix is neglected in this study. Damage is considered as a reduction in the damaged structure, so the damage is considered as reduction in element's modulus of elasticity in this study. Therefore, the elasticity modulus of each damaged element is reduced based on each proposed scenario. In other words, damage in each structural element is determined by the amount in the proposed scenarios. Reduction in elasticity modulus has appeared in member stiffness matrix and then, in $K_{G}$ stiffness matrix.

$$
K_{G}=\sum_{i=1}^{N E}\left(1-B_{i}\right) k_{i}, \quad M_{G}=\sum_{i=1}^{N E} m_{i},
$$

where $K_{G}$ and $M_{G}$ are global stiffness and mass matrices, respectively. $N E$ indicates the number of structural elements. $k_{i}$ and $m_{i}$ present stiffness and mass matrices, correspondingly. Also, it is assumed that no change will happen in the mass of structure before and after the damage. $B_{i}$ is determined as the proposed scenario. In fact, damage severity for each element is displayed by $B_{i}$. The dynamic parameters of the damaged structure are calculated by the following eigenvalue equation:

$$
\left(\left[K_{G}\right]-\omega_{j l}^{2}\left[M_{G}\right]\right)\left\{\varphi_{j l}\right\}=\{0\},
$$

where $\omega_{j l}$ and $\varphi_{j l}$ are the $j$ th natural frequency and mode shape of the damaged structures, respectively.

The objective function of this study is presented in Eq. (10). This equation is based on natural frequencies and mode shapes of damaged and undamaged structures. In this study, damaged structure is estimated by VPS and EVPS algorithms.

$$
\begin{aligned}
\text { Objective Function }= & \sum_{i=1}^{N}\left(\left|\frac{\omega_{i}^{P S}-\omega_{i}^{U S}}{\omega_{i}^{U S}}\right|\right) \\
& +\sum_{j=1}^{D O F}\left(\left|\frac{\left|\varphi_{j i}^{P S}\right|-\left|\varphi_{j i}^{U S}\right|}{\varphi_{j i}^{U S}}\right|\right)
\end{aligned}
$$

where $N$ is the number of considered vibration modes and DOF is the considered structure's degree of freedom number; $\omega_{i}^{P S}$ and $\omega_{i}^{U S}$ are the $i$ th natural 
frequencies of the proposed scenario and undamaged structure, respectively. $\varphi_{j i}^{P S}$ and $\varphi_{j i}^{U S}$ are the values of the $i$ th mode shape and $j$ th degree of freedom, respectively.

\section{Numerical examples}

In this section, the performances of the standard VPS and EVPS algorithms are assessed through four damage detection problems of truss structures. The considered instances consist of four planar and spatial trusses with some single and multiple scenarios. In addition, all problems are investigated in two groups consisting of without-noise and with-noise cases. Problems with noise are considered with small deviations in natural frequencies and experimental mode shapes that are equal to $1 \%$ and $3 \%$, respectively.

In damage detection literature, only a few members are damaged while most are undamaged; thus, a significant mutation is generated by the algorithm. This mutation leads to replacing 0 with the available numbers in $30 \%$ of answers in each iteration. In this study, the scenarios of all the problems are run 30 times and the values of the parameters of the VPS and EVPS algorithms for all problems are as follows.

The total number of iterations, population size, $\omega_{1}, \omega_{2}, P, H M C R, P A R, \alpha$, and $N B$ are 2000, 40, 0.3, $0.3,0.7,0.5,0.2,0.05$, and 4 , respectively. It should be noted that all the problems and scenarios are derived from [9].

\subsection{A 10-bar planar truss}

The first problem is a 10-bar planar truss structure as illustrated in Figure 1. This truss consists of 10 elements and 4 free nodes, and a non-structural mass of $454.0 \mathrm{~kg}$ is added to the free nodes. Also, elasticity modulus, density, and cross sectional area for all elements are $E=69,800 \mathrm{MPa}, \rho=2770 \mathrm{~kg} / \mathrm{m}^{3}$, and $A=0.0025 \mathrm{~m}^{2}$, respectively. Many researchers have investigated this problem as a well-known benchmark in the field of damage detection. The first 8 modes are considered.

Table 1 presents the six scenarios investigated in

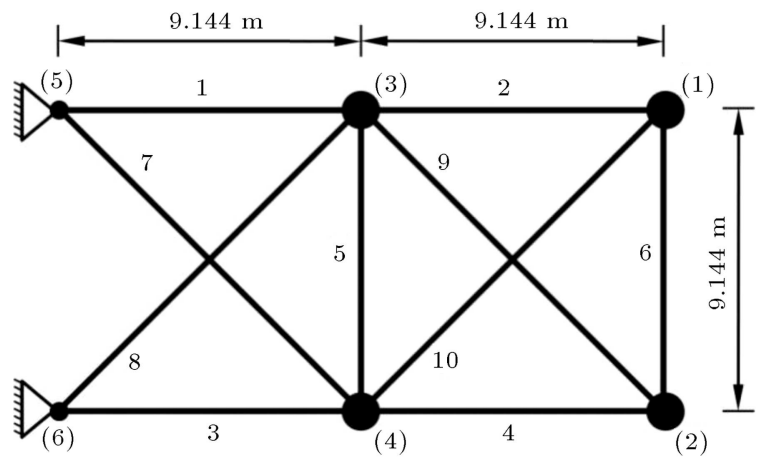

Figure 1. Schematic of the 10-bar planar truss.
Table 1. Six scenarios for the 10-bar planar truss.

\begin{tabular}{ccc}
\hline Scenario & $\begin{array}{c}\text { Damaged } \\
\text { element (s) }\end{array}$ & $\begin{array}{c}\text { Damage } \\
\text { severity }\end{array}$ \\
\hline 1 & 5 & 0.15 \\
2 & 1 & 0.05 \\
3 & 1,10 & $0.05,0.10$ \\
4 & 2,4 & $0.10,0.05$ \\
5 & $1,6,10$ & $0.05,0.15,0.10$ \\
6 & $2,4,5$ & $0.10,0.05,0.15$ \\
\hline
\end{tabular}

this problem. Table 2 illustrates the achieved average, best, and worst results of 30 independent runs for this problem with VPS and EVPS algorithms. Tables 3 and 4 show the damage locations and the damage severity in all scenarios for the best results of both algorithms without noise and with noise, respectively. Results show that the EVPS accurately finds the location and severity of damaged elements in comparison with the VPS algorithm. However, these algorithms cannot find the exact answers for all scenarios.

Figures 2 and 3 present the mean convergence curve for the answers of the sixth scenario without considering noise and evolutionary processes of damage severity to element 5 in the best result for Scenario 1

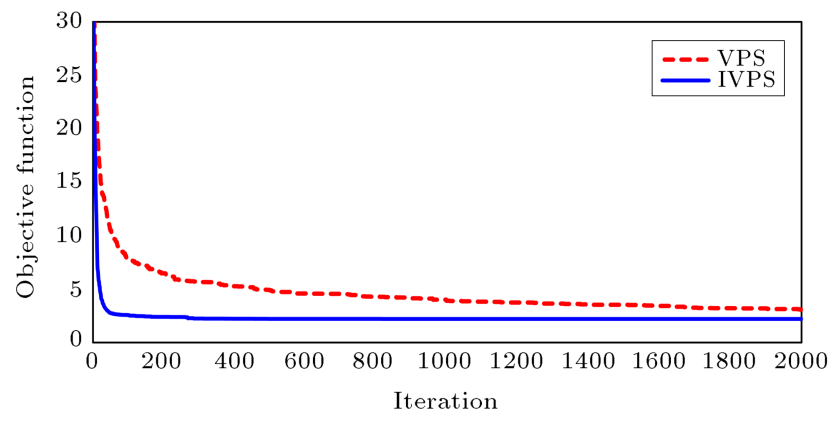

Figure 2. The mean convergence curve for the answers of the sixth scenario without considering noise for both algorithms for the 10-bar planar truss.

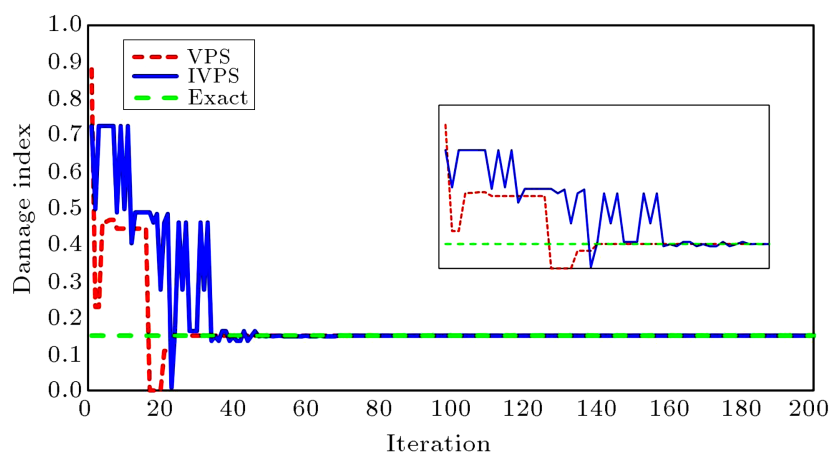

Figure 3. Evolutionary processes of damage severity to element 5 in the best result for scenario 1 without considering noise by both algorithms for the 10-bar truss in the first 200 iterations. 
Table 2. Summary of the objective function values for 6 scenarios without and with noise for VPS and EVPS algorithms for the 10-bar planar truss.

\begin{tabular}{|c|c|c|c|c|c|c|c|c|}
\hline & \multirow{2}{*}{ Scenario } & \multicolumn{3}{|c|}{ VPS algorithm } & \multicolumn{3}{|c|}{ EVPS algorithm } & \multirow{2}{*}{$\begin{array}{c}\text { Objective function } \\
\text { value for } \\
\text { exact answer } \\
\end{array}$} \\
\hline & & Average & Best & Worst & Average & Best & Worst & \\
\hline \multirow{6}{*}{ 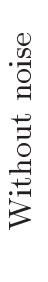 } & 1 & 0.1177 & 0.007 & 0.4852 & 0 & 0 & 0 & 0 \\
\hline & 2 & 0.4939 & 0.0062 & 1.3 & 0.198 & 0 & 1.233 & 0 \\
\hline & 3 & 0.309 & 0.043 & 0.908 & 0.2827 & 0 & 4.25 & 0 \\
\hline & 4 & 3 & 0.672 & 5.609 & 1.543 & 0.001 & 4.807 & 0 \\
\hline & 5 & 2.56 & 1.175 & 3.516 & 0.925 & 0.001 & 4.52 & 0 \\
\hline & 6 & 3.07 & 1.806 & 6.284 & 2.219 & 0.129 & 3.84 & 0 \\
\hline \multirow{6}{*}{ 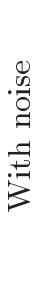 } & 1 & 1.124 & 1.081 & 1.2755 & 1.082 & 1.08 & 1.086 & 0.47 \\
\hline & 2 & 1.164 & 0.9652 & 1.8133 & 1.131 & 0.9411 & 2.724 & 0.505 \\
\hline & 3 & 2.279 & 1.096 & 3.937 & 1.617 & 0.935 & 3.51 & 0.5138 \\
\hline & 4 & 3.267 & 1.145 & 6.196 & 2.202 & 0.937 & 5.32 & 0.499 \\
\hline & 5 & 2.738 & 1.153 & 4.038 & 2 & 0.86 & 4.898 & 0.52 \\
\hline & 6 & 3.086 & 1.788 & 5.86 & 2.379 & 0.919 & 6.134 & 0.522 \\
\hline
\end{tabular}

Table 3. Best answers of the VPS and EVPS algorithms without noise for the 10-bar planar truss.

\begin{tabular}{|c|c|c|c|c|c|c|c|c|c|c|c|c|}
\hline & Scenario & 1 & 2 & 3 & 4 & 5 & 6 & 7 & 8 & 9 & 10 & Damage \\
\hline \multirow{6}{*}{ 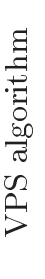 } & 1 & & & & & $x$ & & & & & & 0.1501 \\
\hline & 2 & $x$ & & & & & & & & & & 0.0500 \\
\hline & 3 & $x$ & & & & & & & & & $x$ & $0.0501,0.1001$ \\
\hline & 4 & & $x$ & $\times$ & $x$ & & & & & & & $0.0984,0.0210,0.0406$ \\
\hline & 5 & $x$ & & & & & $x$ & $x$ & & & & $0.0697,0.1432,0.0124$ \\
\hline & 6 & & $x$ & $\times$ & $\times$ & $x$ & & & & & & $0.1199,0.0043,0.0744,0.1397$ \\
\hline \multirow{6}{*}{ 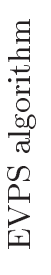 } & 1 & & & & & $x$ & & & & & & 0.15 \\
\hline & 2 & $x$ & & & & & & & & & & 0.05 \\
\hline & 3 & $\times$ & & & & & & & & & $\times$ & $0.0500,0.1000$ \\
\hline & 4 & & $\times$ & & $\times$ & & & & & & & $0.1000,0.05000$ \\
\hline & 5 & $x$ & & & & & $x$ & & & & $\times$ & $0.0499,0.1494,0.0998$ \\
\hline & 6 & & $x$ & & $\times$ & $\times$ & & & & & & $0.0969,0.0458,0.1482$ \\
\hline
\end{tabular}

Table 4. Best answers for VPS and EVPS algorithms with noise for the 10-bar planar truss.

\begin{tabular}{|c|c|c|c|c|c|c|c|c|c|c|c|c|}
\hline & Scenario & 1 & 2 & 3 & 4 & 5 & 6 & 7 & 8 & 9 & 10 & Damage \\
\hline \multirow{6}{*}{ 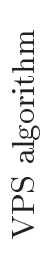 } & 1 & & & & & $x$ & & & $\times$ & $x$ & & $0.1496,0.0009,0.0058$ \\
\hline & 2 & $x$ & $x$ & & & & & & & & & $0.0479,0.0009$ \\
\hline & 3 & $x$ & & & & & & & & & $\times$ & $0.0480,0.1137$ \\
\hline & 4 & & $x$ & & $x$ & & & & & & & $0.1033,0.0489$ \\
\hline & 5 & $\times$ & & & & & $\times$ & & & & $\times$ & $0.0461,0.1533,0.1148$ \\
\hline & 6 & & $x$ & & $x$ & $x$ & & & & & & $0.0656,0.0155,0.1125$ \\
\hline \multirow{6}{*}{ 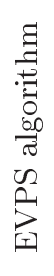 } & 1 & & & & & $x$ & & & & $x$ & & $0.1509,0.0041$ \\
\hline & 2 & $x$ & & & & & & & & $x$ & & $0.0506,0.0055$ \\
\hline & 3 & $\times$ & & & & & & & & & $x$ & $0.0498,0.1005$ \\
\hline & 4 & & $\times$ & & $x$ & & & $x$ & & & & $0.1009,0.0493,0.0021$ \\
\hline & 5 & $\times$ & & & & & $\times$ & & & & $x$ & $0.0504,0.1470,0.1011$ \\
\hline & 6 & & $x$ & & $x$ & $x$ & & & & & & $0.0979,0.0484,0.1425$ \\
\hline
\end{tabular}


without considering noise in the 200 first iterations by both algorithms for the 10-bar truss, respectively.

\subsection{A 15-bar planar truss}

The second problem is a 15-bar planar truss structure as shown in Figure 4. This truss consists of 10 elements and 6 free nodes. Also, the elasticity modulus, density, and cross sectional area for all the elements are $E=$ $200 \times 10^{9} \mathrm{~N} / \mathrm{m}^{2}, \rho=7800 \mathrm{~kg} / \mathrm{m}$, and $A=0.001 \mathrm{~m}^{2}$, respectively. All modes are considered. Also, all vertical and horizontal elements are assumed to be equal to $1.0 \mathrm{~m}$.

Table 5 shows the six scenarios investigated in

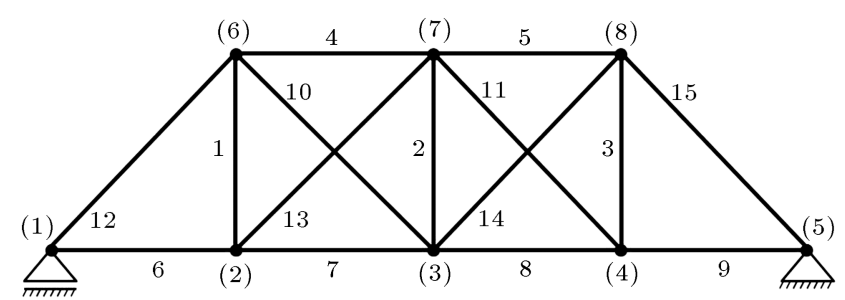

Figure 4. Schematic of the 15-bar planar truss.

Table 5. Scenarios for the 15-bar planar truss.

\begin{tabular}{ccc}
\hline Scenario & $\begin{array}{c}\text { Damaged } \\
\text { element (s) }\end{array}$ & $\begin{array}{c}\text { Damage } \\
\text { severity }\end{array}$ \\
\hline 1 & 7 & 0.18 \\
2 & 13 & 0.33 \\
3 & 6,11 & $0.20,0.15$ \\
4 & 2,7 & $0.20,0.10$ \\
5 & $1,7,13$ & $0.47,0.25,0.30$ \\
6 & $2,6,11$ & $0.16,0.20,0.20$ \\
\hline
\end{tabular}

this problem. Table 6 presents the achieved average, best, and worst results of 30 independent runs in this problem with the VPS and EVPS algorithms. Tables 7 and 8 show the damage locations and damage severity in all scenarios for the best results of both algorithms without noise and with noise, respectively.

\subsection{A 25-bar planar truss}

The third problem is a 25-bar spatial truss structure as shown in Figure 5. This truss consists of 25 elements and 6 free nodes. Also, the elasticity modulus, density, and cross sectional area for all elements are $E=10 \mathrm{GPa}, \rho=0.1 \mathrm{~kg} / \mathrm{m}^{3}$, and $A=0.001 \mathrm{~m}^{2}$, respectively. The first 6 modes are considered.

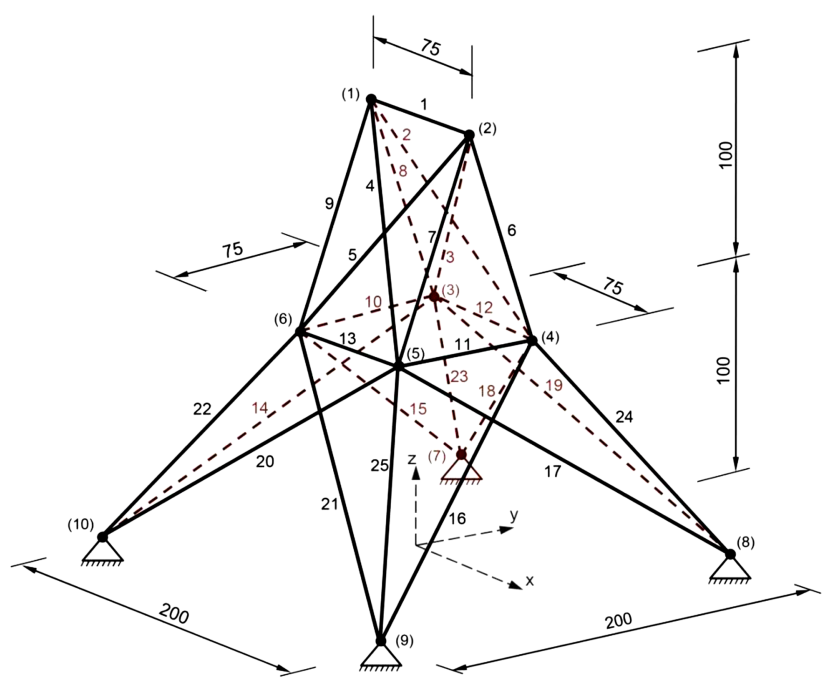

Figure 5. Schematic of the 25-bar spatial truss (all the dimensions are in $\mathrm{mm}$ ).

Table 6. Summary of the objective function values for 6 scenarios without and with noise for the VPS and EVPS algorithms for the 15-bar planar truss.

\begin{tabular}{|c|c|c|c|c|c|c|c|c|}
\hline \multirow{2}{*}{\multicolumn{2}{|c|}{ Scenario }} & \multicolumn{3}{|c|}{ VPS algorithm } & \multicolumn{3}{|c|}{ EVPS algorithm } & \multirow{2}{*}{$\begin{array}{c}\text { Objective function } \\
\text { value for } \\
\text { exact answer } \\
\end{array}$} \\
\hline & & Average & Best & Worst & Average & Best & Worst & \\
\hline \multirow{6}{*}{ 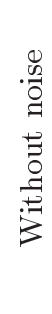 } & 1 & 10.92 & 1.41 & 23.97 & 0.89 & 0 & 26.91 & 0 \\
\hline & 2 & 20.03 & 1.76 & 67.36 & 2.33 & 0 & 24 & 0 \\
\hline & 3 & 35.59 & 12.49 & 56.45 & 11.26 & 0 & 33.19 & 0 \\
\hline & 4 & 40.46 & 17.76 & 75.50 & 13.69 & 0.002 & 90.48 & 0 \\
\hline & 5 & 22.34 & 7.62 & 35.53 & 7.96 & 0.083 & 29.53 & 0 \\
\hline & 6 & 21.90 & 7.10 & 34.33 & 8.16 & 0.080 & 19.60 & 0 \\
\hline \multirow{6}{*}{ 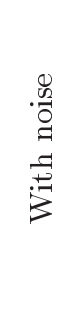 } & 1 & 12.49 & 2.66 & 31.21 & 4.19 & 2.52 & 30.80 & 2.54 \\
\hline & 2 & 20.42 & 3.18 & 43.79 & 2.49 & 2.46 & 2.49 & 2.50 \\
\hline & 3 & 40.91 & 17.28 & 63.53 & 11.42 & 2.49 & 30.93 & 2.50 \\
\hline & 4 & 40.99 & 12.88 & 75.60 & 8.21 & 2.53 & 23.46 & 2.54 \\
\hline & 5 & 26.33 & 11.04 & 44.29 & 11.35 & 2.39 & 26.01 & 2.70 \\
\hline & 6 & 22.02 & 14.84 & 31.51 & 8.09 & 2.37 & 30.15 & 2.40 \\
\hline
\end{tabular}


Table 7. Best answers of the VPS and EVPS algorithms without noise for the 15-bar planar truss.

\begin{tabular}{|c|c|c|c|c|c|c|c|c|c|c|c|c|c|c|c|c|c|}
\hline & Scenario & 1 & 2 & 3 & 4 & 5 & 6 & 7 & 8 & 9 & 10 & 11 & 12 & 13 & 14 & 15 & Damage \\
\hline \multirow{6}{*}{ 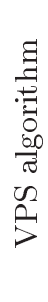 } & 1 & & & & & & & $x$ & & & & & & & & & 0.1745 \\
\hline & 2 & & & & & & & & & & & & & $\times$ & & & 0.3234 \\
\hline & 3 & & & & & & $x$ & & & & & $\times$ & & & & & $0.2170,0.1343$ \\
\hline & 4 & & $x$ & & & $x$ & & $x$ & & & $\times$ & $x$ & & & & & $0.2389,0.0084,0.0911,0.0171,0.0443$ \\
\hline & 5 & $x$ & & & & & & $x$ & & & $x$ & & & $\times$ & & & $0.4485,0.2183,0.0010,0.2624$ \\
\hline & 6 & & $x$ & & & & $x$ & $x$ & & & & $\times$ & & & & & $0.1768,0.2194,0.0133,0.2429$ \\
\hline \multirow{6}{*}{ 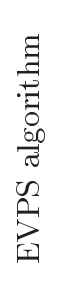 } & 1 & & & & & & & $x$ & & & & & & & & & 0.18 \\
\hline & 2 & & & & & & & & & & & & & $x$ & & & 0.33 \\
\hline & 3 & & & & & & $x$ & & & & & $x$ & & & & & $0.20000,0.1500$ \\
\hline & 4 & & $x$ & & & & & $x$ & & & & & & & & & $0.2000,0.10000$ \\
\hline & 5 & $x$ & & & & & & $x$ & & & & & & $x$ & & & $0.4682,0.2481,0.3029$ \\
\hline & 6 & & $x$ & & & & $x$ & & & & & $\times$ & & & & & $0.1601,0.2003,0.2009$ \\
\hline
\end{tabular}

Table 8. Best answers for the VPS and EVPS algorithms with noise for the 15-bar planar truss.

\begin{tabular}{|c|c|c|c|c|c|c|c|c|c|c|c|c|c|c|c|c|c|}
\hline & Scenario & 1 & 2 & 3 & 4 & 5 & 6 & 7 & 8 & 9 & 10 & 11 & 12 & 13 & 14 & 15 & Damage \\
\hline \multirow{6}{*}{ 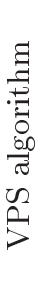 } & 1 & & & & & & & $x$ & & & & & & & & & 0.1790 \\
\hline & 2 & & & & $x$ & & & & & & & & & $x$ & & & $0.0024,0.3336$ \\
\hline & 3 & & & & & & $x$ & & $\times$ & & & $x$ & & & & & $0.2529,0.0219,0.1427$ \\
\hline & 4 & & $x$ & & & & $x$ & $\times$ & & & & & & & & & $0.2124,0.0189,0.0668$ \\
\hline & 5 & $x$ & & $x$ & & & & $\times$ & & $x$ & & & $x$ & & & & $0.4606,0.0091,0.2449,0.0623,0.3605$ \\
\hline & 6 & & $x$ & & & & $x$ & $\times$ & & & $x$ & $x$ & & & & & $0.2418,0.2051,0.0079,0.0160,0.2313$ \\
\hline \multirow{6}{*}{ 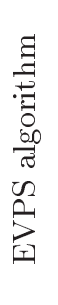 } & 1 & $x$ & & & & & & $x$ & & & & & & & & & $0.0001,0.1803$ \\
\hline & 2 & & & & & & & & $\times$ & & & & & $\times$ & & & $0.0012,0.3299$ \\
\hline & 3 & & & & & & $x$ & & & & & $\times$ & & & & & $0.1998,0.1500$ \\
\hline & 4 & & $x$ & & & & & $x$ & & & & & & & & & $0.1999,0.1002$ \\
\hline & 5 & $x$ & & & & & & $x$ & & & & & $x$ & & & & $0.4697,0.2547,0.3001$ \\
\hline & 6 & & $x$ & & & & $x$ & & & & & $x$ & & & & & $0.1600,0.2006,0.2007$ \\
\hline
\end{tabular}

Table 9. Six scenarios for the 25-bar spatial truss.

\begin{tabular}{ccc}
\hline Scenario & $\begin{array}{c}\text { Damaged } \\
\text { element (s) }\end{array}$ & $\begin{array}{c}\text { Damage } \\
\text { severity }\end{array}$ \\
\hline 1 & 19 & 0.18 \\
2 & 9 & 0.16 \\
3 & 7,23 & $0.15,0.20$ \\
4 & 4,11 & $0.20,0.10$ \\
5 & $2,10,18$ & $0.20,0.25,0.15$ \\
6 & $7,17,23$ & $0.15,0.15,0.20$ \\
\hline
\end{tabular}

Table 9 shows the six scenarios investigated in this problem. Table 10 illustrates the achieved average, best, and worst results of 30 independent runs in this problem with VPS and EVPS algorithms. Tables 11 and 12 show the damage locations and the damage severity in all scenarios for the best results of both algorithms without noise and with noise, respectively.

\subsection{A 72-bar spatial truss}

The fourth problem is a 72-bar spatial truss structure as illustrated in Figure 6. This truss consists of 72 elements and 16 free nodes. Elasticity modulus, density, and cross sectional area for all elements are $E=$ $6.98 \times 10 \mathrm{~N} / \mathrm{m}^{2}, \rho=2770 \mathrm{~kg} / \mathrm{m}^{3}$, and $A=0.0025 \mathrm{~m}^{2}$, respectively. The first 16 modes are considered.

Table 13 presents the six scenarios investigated in this problem. Table 14 illustrates the achieved average, best, and worst results of 30 independent runs in this problem with VPS and EVPS algorithms. Tables 15 and 16 show the damage locations and damage severity in all scenarios for the best results of both algorithms 
Table 10. Summary of the objective function values for 6 scenarios without and with noise for VPS and EVPS algorithms for the 25-bar spatial truss.

\begin{tabular}{|c|c|c|c|c|c|c|c|c|}
\hline & \multirow{2}{*}{ Scenario } & \multicolumn{3}{|c|}{ VPS algorithm } & \multicolumn{3}{|c|}{ EVPS algorithm } & \multirow{2}{*}{$\begin{array}{c}\text { Objective function } \\
\text { value for } \\
\text { exact answer }\end{array}$} \\
\hline & & Average & Best & Worst & Average & Best & Worst & \\
\hline \multirow{6}{*}{ 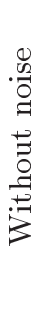 } & 1 & 489.8604 & 102.2595 & 805.4285 & 6.608262 & 0 & 69.36433 & 0 \\
\hline & 2 & 486.107 & 112.7481 & 1018.282 & 7.393969 & 0 & 46.36334 & 0 \\
\hline & 3 & 150.1585 & 55.96212 & 264.8678 & 7.363929 & 0.000739 & 49.10197 & 0 \\
\hline & 4 & 372.7269 & 31.76866 & 823.1844 & 8.170469 & 0.000144 & 33.58254 & 0 \\
\hline & 5 & 116.8389 & 28.51743 & 193.6074 & 11.16476 & 0.011579 & 44.48945 & 0 \\
\hline & 6 & 191.9109 & 78.87526 & 448.6217 & 33.23011 & 0.037428 & 80.68723 & 0 \\
\hline \multirow{6}{*}{ 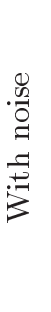 } & 1 & 455.9204 & 100.6871 & 865.25 & 26.23318 & 1.66506 & 440.6707 & 1.67 \\
\hline & 2 & 445.4167 & 107.9602 & 917.9452 & 8.598463 & 1.673222 & 46.53423 & 1.69 \\
\hline & 3 & 141.2858 & 47.52661 & 309.7607 & 7.915229 & 1.60966 & 46.10536 & 1.62 \\
\hline & 4 & 378.2894 & 104.4001 & 1040.176 & 7.52212 & 1.627496 & 28.81299 & 1.63 \\
\hline & 5 & 109.1755 & 41.58663 & 192.6811 & 8.230128 & 1.689254 & 33.91095 & 1.69 \\
\hline & 6 & 184.8772 & 91.97713 & 378.5631 & 36.67907 & 1.824269 & 71.48046 & 1.70 \\
\hline
\end{tabular}

Table 11. Best answers of VPS and EVPS algorithms without noise for the 25-bar spatial truss.

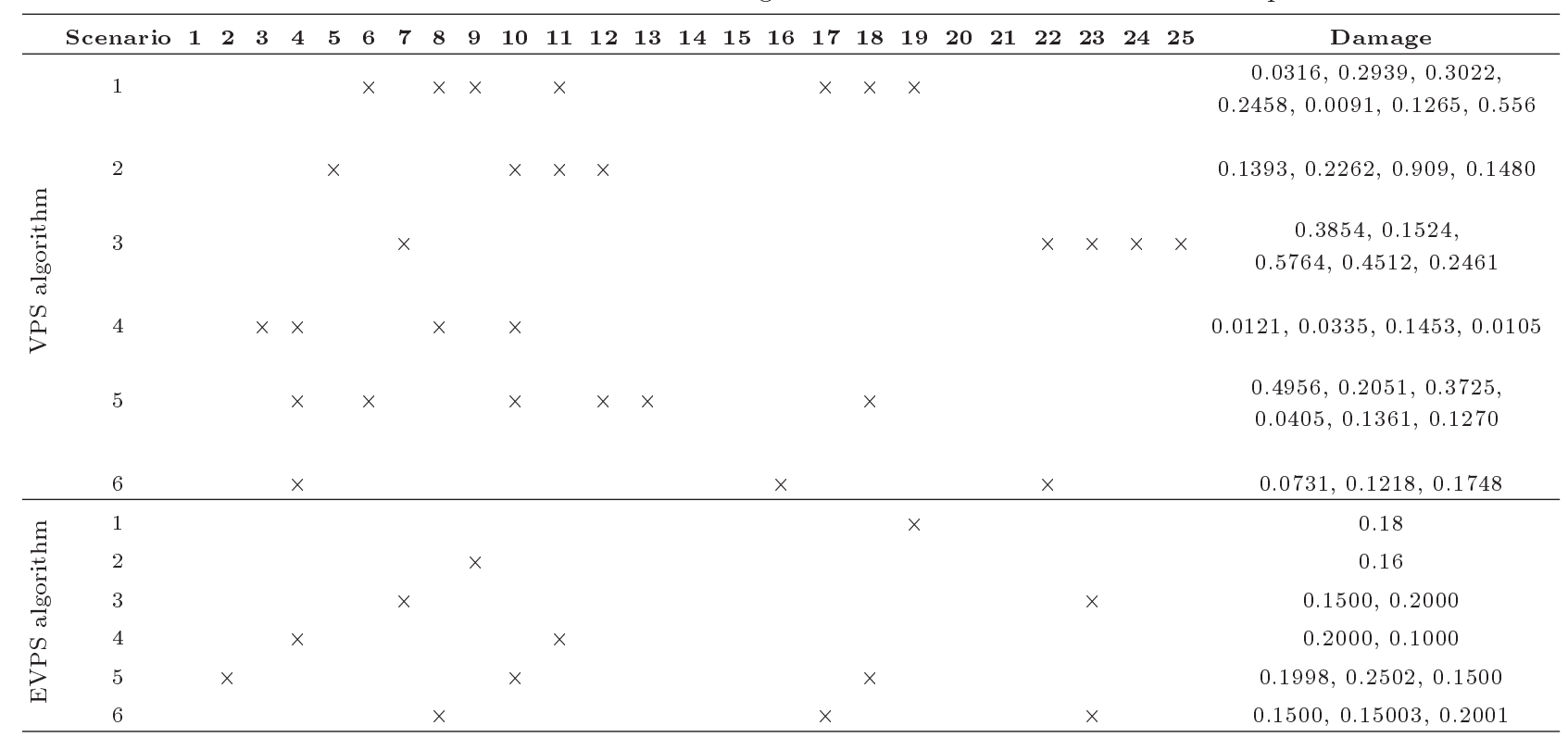

without noise and with noise, respectively. Results are also compared with the SDE algorithm.

\section{Conclusion}

Vibrating Particles System algorithm has recently been developed. This algorithm was inspired by one degree of freedom systems with viscous damping. In this study, the enhanced vibrating particles system algorithm was introduced as the EVPS algorithm. The improvement included adding new parameters and changes in equations of the VPS algorithm. To compare the efficacy of the algorithms, 4 problems were studied for damage detection of truss structures considering 30 independent runs. The studied damage detection problems included damage to one and several elements. Additionally, problems with noise and without noise were studied. In these problems, the objective function was considered using natural frequencies and mode shapes. A significant mutation was used in all the damage detection problems, which made the algorithm reach an answer faster and more accurately. Results showed that the EVPS algorithm obtained better mean than the VPS algorithm did and 
Table 12. Best answers for VPS and EVPS algorithms with noise for the 25-bar spatial truss.

\begin{tabular}{|c|c|c|c|c|c|c|c|c|c|c|c|c|c|c|c|c|c|c|c|c|c|c|c|c|c|c|c|}
\hline & Scenario & 1 & 2 & 3 & 4 & 5 & 6 & 7 & 8 & 9 & 10 & 11 & 12 & 13 & 14 & 15 & 16 & 17 & 18 & 19 & 20 & 21 & 22 & 23 & 24 & 25 & Damage \\
\hline \multirow{6}{*}{ 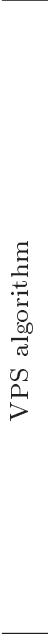 } & 1 & $\times$ & & $\times$ & & $\times$ & & & & $\times$ & $\times$ & & & $\times$ & & & & & & $\times$ & & $\times$ & $\times$ & & $\times$ & & $\begin{array}{c}0.3966,0.2391,0.2214 \\
0.01800,0.36515,0.0544 \\
0.4156,0.0385,0.0491,0.2476\end{array}$ \\
\hline & 2 & $\times$ & & $\times$ & & $\times$ & $\times$ & $x$ & & $\times$ & & $\times$ & & $x$ & & & & & & & & & & & & & $\begin{array}{l}0.2729,0.0787,0.1816,0.4899 \\
0.4327,0.1029,0.7218,0.3736\end{array}$ \\
\hline & 3 & & $x$ & $x$ & $x$ & $\times$ & $\times$ & & & & & & & & & & & & & & & & & & & $x$ & $\begin{array}{c}0.1798,0.4765,0.2192 \\
0.5338,0.3478,0.0480\end{array}$ \\
\hline & 4 & $x$ & $\times$ & & $x$ & $\times$ & $\times$ & & & $\times$ & & $\times$ & & & & & & & & & & & & & & & $\begin{array}{c}0.4331,0.7407,0.5277,0.1592 \\
0.0532,0.1886,0.3286\end{array}$ \\
\hline & 5 & $\times$ & & & $x$ & & $\times$ & $x$ & $x$ & $\times$ & $\times$ & & $\times$ & & & & & & $x$ & & & $\times$ & & & & & $\begin{array}{c}0.2423,0.5242,0.0526 \\
0.1341,0.2145,0.0663 \\
0.1955,0.0463,0.2378,0.0441\end{array}$ \\
\hline & 6 & & & $\times$ & & $\times$ & & $x$ & & & & & & $x$ & & & & & & & & & & & $x$ & $x$ & $\begin{array}{c}0.5377,0.6092,0.3271,0.3279 \\
0.0830,0.4709,0.0227\end{array}$ \\
\hline \multirow{6}{*}{ 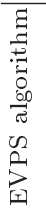 } & 1 & & & & & & & & & & & & & & & & & & & $x$ & & $\times$ & & & & & $0.1804,0.0001$ \\
\hline & 2 & $x$ & & & & & & & & $x$ & & & & & & & & & & & & & & & & & $0.0024,0.1600$ \\
\hline & 3 & & & & & & & $x$ & & & & & & & & & & & & & & & & $x$ & & & $0.1495,0.2003$ \\
\hline & 4 & & & & $x$ & & & & & & & $\times$ & & & & & & & & & & & & & & & $0.2001,0.0999$ \\
\hline & 5 & & $\times$ & & & & & & & & $\times$ & & & & & & & & $\times$ & & & & & & & & $0.2007,0.2494,0.1498$ \\
\hline & 6 & & & & & & & $x$ & & & & & & & & & & $x$ & & & & & & $x$ & & & $0.1491,0.1496,0.2000$ \\
\hline
\end{tabular}

Table 13. Four scenarios for the 72-bar spatial truss.

\begin{tabular}{|c|c|c|}
\hline Scenario & $\begin{array}{c}\text { Damaged } \\
\text { element (s) }\end{array}$ & $\begin{array}{l}\text { Damage } \\
\text { severity }\end{array}$ \\
\hline 1 & 10 & 0.20 \\
\hline 2 & 55 & 0.15 \\
\hline 3 & 4,58 & $0.10,0.15$ \\
\hline 4 & 14,51 & $0.13,0.10$ \\
\hline
\end{tabular}

it gained the best result for all cases. The EVPS algorithm had high capability of escaping from local optima compared with the VPS algorithm. In addition, the EVPS had a higher speed and was more accurate than the VPS algorithm. Comparison of VPS and
Table 15. Best answers of VPS, EVPS, and SDE algorithms without noise for the 72-bar spatial truss***.

\begin{tabular}{cccc}
\hline & Scenario & $\begin{array}{c}\text { Damaged } \\
\text { elements }\end{array}$ & $\begin{array}{c}\text { Damage } \\
\text { severity }\end{array}$ \\
\hline EVPS & 1 & 10 & 0.2000 \\
algorithm & 2 & 55 & 0.1500 \\
& 3 & 4,58 & $0.1000,0.1500$ \\
& 4 & 14,51 & $0.1300,0.1000$ \\
SDE & 1 & 10 & 0.2000 \\
algorithm [9] & 2 & 55 & 0.1500 \\
& 3 & 4,58 & $0.1000,0.1500$ \\
& 4 & 14,51 & $0.1300,0.1000$ \\
\hline
\end{tabular}

*** Since the answers of VPS algorithm are inappropriate for this problem, they are not provided.

Table 14. Summary of the objective function values for 4 scenarios without and with noise for VPS and EVPS algorithms for the 72-bar spatial truss ${ }^{* * *}$.

\begin{tabular}{|c|c|c|c|c|c|c|c|c|}
\hline & \multirow{2}{*}{ Scenario } & \multicolumn{3}{|c|}{ VPS algorithm } & \multicolumn{3}{|c|}{ EVPS algorithm } & \multirow{2}{*}{$\begin{array}{c}\text { Objective function } \\
\text { value for } \\
\text { exact answer }\end{array}$} \\
\hline & & Average & Best & Worst & Average & Best & Worst & \\
\hline \multirow{4}{*}{ 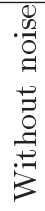 } & 1 & 1235.084 & 1039.824 & 1361.238 & 48.25944 & 0 & 132.0679 & 0 \\
\hline & 2 & 1405.002 & 1219.066 & 1595.558 & 54.27792 & 0 & 945.8037 & 0 \\
\hline & 3 & 1724.782 & 1456.972 & 1949.947 & 89.87375 & 0.0698 & 148.2069 & 0 \\
\hline & 4 & 1849.881 & 1646.47 & 2127.439 & 76.80913 & 0.000938 & 241.9281 & 0 \\
\hline \multirow{4}{*}{ 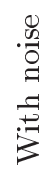 } & 1 & 1220.854 & 954.9313 & 1373.057 & 68.00602 & 11.35927 & 222.2335 & 11.41 \\
\hline & 2 & 1412.465 & 1212.728 & 1541.318 & 35.78667 & 11.45204 & 69.85047 & 11.47 \\
\hline & 3 & 1698.849 & 1254.077 & 1927.893 & 95.26347 & 11.62875 & 172.9505 & 11.66 \\
\hline & 4 & 1776.609 & 1519.187 & 2037.711 & 53.76691 & 11.76709 & 205.5731 & 11.78 \\
\hline
\end{tabular}

*** Since the answers of VPS algorithm are inappropriate for this problem, they are not provided. 


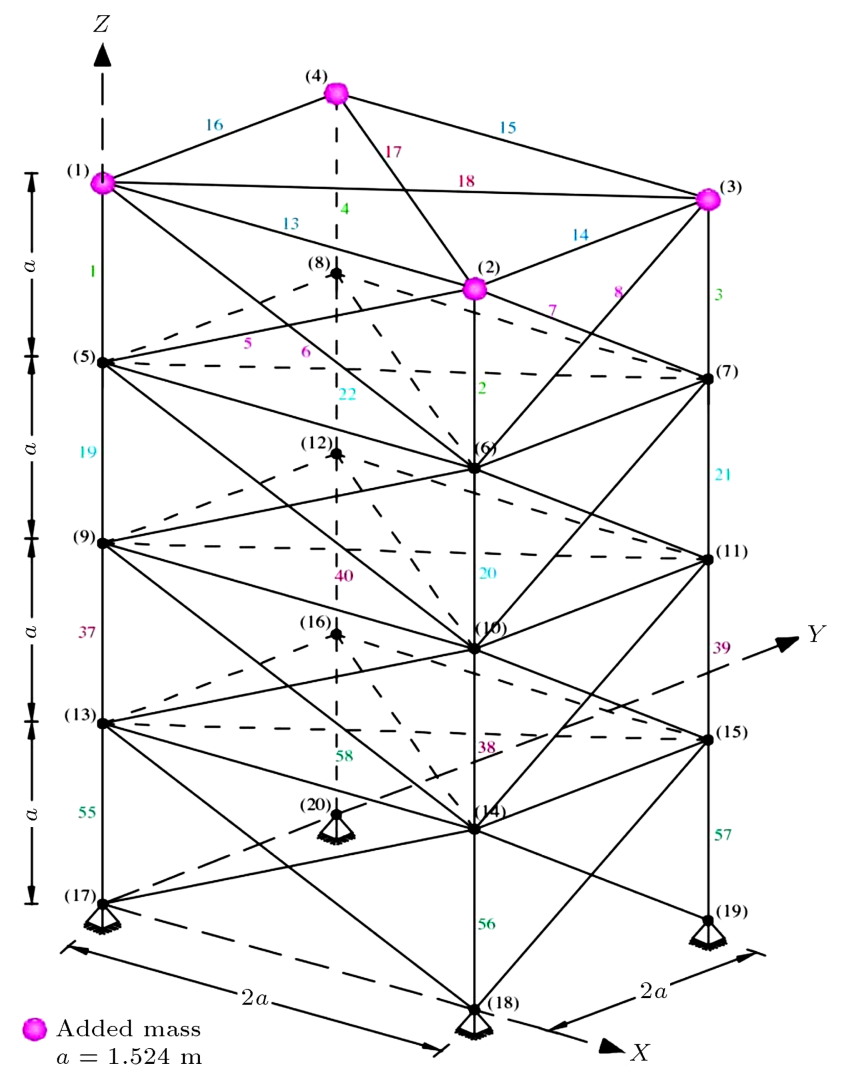

Figure 6. Schematic of the 72-bar spatial truss.

Table 16. Best answers for VPS, EVPS, and SDE algorithms with noise for the 72-bar spatial truss ${ }^{* * *}$.

\begin{tabular}{cccc}
\hline & Scenario & $\begin{array}{c}\text { Damaged } \\
\text { elements }\end{array}$ & $\begin{array}{c}\text { Damage } \\
\text { severity }\end{array}$ \\
\hline EVPS & 1 & 10,53 & $0.2000,0.0039$ \\
algorithm & 2 & 37,55 & $0.0006,0.1495$ \\
& 3 & $4,58,68$ & $0.1000,0.1499,0.0027$ \\
& 4 & 14,51 & $0.1303,0.0992$ \\
SDE & 1 & 10,69 & $0.2000,0.0100$ \\
algorithm [9] & 4 & $14,50,51$ & $0.1300,0.0100,0.0700$ \\
*** Since the answers of VPS algorithm are inappropriate for \\
this problem, they are not provided.
\end{tabular}

EVPS for other structural optimization problems is recommended.

\section{References}

1. Kaveh, A., Advances in Metaheuristic Algorithms for Optimal Design of Structures, Springer International Publishing, Switzerland (2017).

2. Sharafi, P., Hadi, M.N., and Teh, L.H. "Heuristic approach for optimum cost and layout design of 3D reinforced concrete frames", Journal of Structural Engineering, 138(7), pp. 853-863 (2011).

3. Sharafi, P., Hadi, M.N., and Teh, L.H. "Optimum column layout design of reinforced concrete frames under wind loading", Topics on the Dynamics of Civil Structures, 1, pp. 327-340 (2012).

4. Sharafi, P., Hadi, M.N., and Teh, L.H. "Cost optimization of column layout design of reinforced concrete buildings", Metaheuristic Applications in Structures and Infrastructures, pp. 129-46 (2013).

5. Holland, J.H., Adaptation in Natural and Artificial Systems: An Introductory Analysis with Applications to Biology, Control, and Artificial Intelligence, University of Michigan Press (1975).

6. Eberhart, R. and Kennedy, J. "A new optimizer using particle swarm theory", In: Proceedings of the Sixth International Symposium on Micro Machine and Human Science, 43, IEEE, New York (1995).

7. Kaveh, A. and Talatahari, S. "A novel heuristic optimization method: charged system search", Acta Mech., 213(3-4), pp. 267-289 (2010).

8. Gandomi, A.H. and Alavi, A.H. "Krill herd: a new bioinspired optimization algorithm", Commun. Nonlinear Sci. Numer. Simul, 17(12), pp. 4831-4845 (2012).

9. Kaveh, A., Hoseini Vaez, S.R., Hosseini, P., and Fallah, N. "Detection of damage in truss structures using simplified dolphin echolocation algorithm based on modal data", Smart Struct. Syst., 18(5), pp. 983-1004 (2016).

10. Kaveh, A. and Mahdavi, V.R. "Colliding bodies optimization: a novel meta-heuristic method", Compu. Struct., 139, pp. 18-27 (2014).

11. Kaveh, A. and Ilchi Ghazaan, M. "Enhanced colliding bodies optimization for design problems with continuous and discrete variables", Adv. Eng. Softw., 77, pp. 66-75 (2014).

12. Talatahari, S., Gandomi, A.H., Yang, X.-S., and Deb, S. "Optimum design of frame structures using the eagle strategy with differential evolution", Eng. Struct., 91, pp. 16-25 (2015).

13. Kaveh, A. and Khayatazad, M. "A new meta-heuristic method: ray optimization", Comput. Struct., 112113, pp. 283-294 (2012).

14. Kaveh, A. and Bakhshpoori, T. "An accelerated water evaporation optimization formulation for discrete optimization of skeletal structures", Comput. Struct., 177, pp. 218-228 (2016).

15. Kaveh, A., Hoseini Vaez, S.R., and Hosseini, P. "Modified Dolphin Monitoring for weight optimization of frame structures", Periodica Polytechnica. Civil Engineering, Online First (2018) paper 12544. https://doi.org/10.3311/PPci.12544

16. Kaveh, A. and Ilchi Ghazaan, M. "Vibrating particles system algorithm for truss optimization with multiple natural frequency constraints", Acta Mech., 228(1), pp. 307-322 (2017).

17. Azam, S.E., Online Damage Detection in Structural Systems: Applications of Proper Orthogonal Decomposition, and Kalman and Particle Filters, Springer Science \& Business Media (2014). 
18. Chang, F.-K., Structural Health Monitoring: Current Status and Perspectives, CRC Press (1998).

19. Kaveh, A. and Mahdavi, V.R. "Damage identification of truss structures using CBO and ECBO algorithms", Asian J. Civil Eng., 17(1), pp. 75-89 (2016).

20. Kaveh, A. and Maniat, M. "Damage detection based on MCSS and PSO using modal data", Smart Struct. Syst., Techno Press, 15(5), pp. 1253-1270 (2015).

21. Kaveh, A. and Zolghadr, A. "An improved CSS for damage detection of truss structures using changes in natural frequencies and mode shapes", Adv. Eng. Softw., 80, pp. 93-100 (2015).

22. Zamani Mehian, S.H., Razavian Amiri, S.A., Maniat, M., and Nowruzpour, M. "Structural health monitoring using optimising algorithms based on flexibility matrix approach and combination of natural frequencies and mode shapes", International Journal of Structural Engineering, 7(4), pp. 398-411 (2016).

23. Hoseini Vaez, S.R. and Fallah, N. "Damage detection of thin plates using GA-PSO algorithm based on modal data", Arabian J. Sci. Eng., pp. 1-13 (2016).

24. Kaveh, A. and Ilchi Ghazaan, M. "Vibrating particles system algorithm for truss optimization with multiple natural frequency constraints", Acta Mech., Published Online, pp. 1-16 (2016).

\section{Biographies}

Ali Kaveh was born in 1948 in Tabriz, Iran. After graduation from the Department of Civil Engineering at the University of Tabriz in 1969, he continued his studies on Structures at Imperial College of Science and Technology at London University, and received his MSc, DIC, and PhD degrees in 1970 and 1974, respectively. He then joined the Iran University of Science and Technology. Professor Kaveh is the author of 610 papers published in international journals and 145 papers presented at national and international conferences. He has authored 23 books in Persian and 8 books in English published by Wiley, Research Studies Press, American Mechanical Society, and Springer.

Seyed Rohollah Hoseini Vaez is currently an Associate Professor at the University of Qom. He teaches courses on the finite element methods, structural optimization, advanced reinforced concrete structures, and earthquake engineering. Dr. Hoseini Vaez's research interests include system identification, nearfault ground motions, finite element method, and soft computing.

Pedram Hosseini was born in 1989 in Mahallat. He obtained his BSc degree in Civil Engineering from University of Tafresh in 2012, and his MSc degree in Structural Engineering from Iran University of Science and Technology in 2014. At present, he is a PhD candidate at the University of Qom. His main research interests include direct and inverse optimization problems and meta-heuristic algorithms. 